\title{
EFFECT OF YEASTS ON THE AROMA PROFILE OF SAUVIGNON BLANC VARIETAL WINE
}

\author{
Božena Průšová ${ }^{1}$, Jiří Sochor ${ }^{1}$, Mojmír Baron ${ }^{1}$, Michal Kumsta ${ }^{1}$ \\ ${ }^{1}$ Department of Viticulture and Enology, Faculty of Horticulture, Mendel University in Brno, Valtická 337, CZ-691 \\ 44 Lednice, Czech Republic
}

\begin{abstract}
PRŮŠOVÁ BOŽENA, SOCHOR JIŘÍ, BARON MOJMÍR, KUMSTA MICHAL. 2018. Effect of Yeasts on the Aroma Profile of Sauvignon Blanc Varietal Wine. Acta Universitatis Agriculturae et Silviculturae Mendelianae Brunensis, 66(4): 889-896.

In this study effects of commercial yeast preparations on the aromatic profile of Sauvignon Blanc varietal wine were investigated. Grape juice was divided to 7 experimental variants and fermented spontaneously and using 6 commercial strains of Saccharomyces cerevisiae. In final wine samples, essential analytical parameters and selected aromatic compounds were analysed. The highest content of esters was found out in samples fermented by spontaneous micro-flora; in this case, concentrations of ethyl hexanoate, ethyl octanoate and ethyl decanoate were $682 \mu \mathrm{g} / \mathrm{L}, 735 \mu \mathrm{g} / \mathrm{L}$ and $162 \mu \mathrm{g} / \mathrm{L}$, respectively. The highest content of acetates was recorded in samples fermented by yeast Vulcaferm Sauvignon; concentrations of isoamyl acetate, 2-phenylethyl acetate and isobutyl acetate were $7.8 \mathrm{mg} / \mathrm{L}, 244 \mu \mathrm{g} / \mathrm{L}$ and $137 \mu \mathrm{g} / \mathrm{L}$, respectively.

Yeast strain suitable for cold fermentation (Oenoferm Fredo) produced high amounts of ethyl esters and acetates. As far as the sensory evaluation was concerned, the best rating got the sample fermented by these yeasts; it showed a high degree of smell and flavour cleanness as well as a very good overall harmony.
\end{abstract}

Keywords: yeasts, fermentation, aromatic profile, Sauvignon Blanc, GC-MS analysis

\section{INTRODUCTION}

Enologists consider the process of alcoholic fermentation as one of the most important stages within the process of wine making. According to the opinion of many enologists, the use of pure yeast cultures is essential for a good course of the fermentation process because it results in a high concentration of yeasts and, thus, also in a rapid initiation of alcoholic fermentation. a rapid beginning of the process of fermentation reduces the possibility of wine contamination with undesirable microorganisms (Ribéreau-Gayon et al., 2006).

The final wine aroma is determined by mutual interactions of a great amount of aromatic compounds that are present in grape juice. In grapes, these substances occur in skins of berries. Berries also contain small amounts of some volatile substances that could be sensed by the smell. These aromatic compounds consist of terpene-based substances that are glycosidically bond with sugars; this means that they are not volatile and therefore inactive from the olfactoric point of view. The aroma is released only after the cleaving of sugars (Ribéreau-Gayon et al., 2006). The aromatic potential of grapes is influenced by the content of glycosides in wine or in juice. The splitting of glycosides that takes place in the course of processing of grapes causes a release of volatile and aromatic aglycones (Mendes Ferreira et al., 2001).

The wine aroma has four parts and can be therefore divided into four separate groups. The first one is defined as the primary aroma: it is determined by aromatic compounds occurring in undamaged cells of grapevine berries (Moreno-Arribas and Polo, 2009). The second group is called secondary aroma and it is characterised by aromatic compounds 
released in the course of processing of grapes. The third part is referred to as the fermentation aroma and it consists of those aromatic substances that are released during fermentation. These substances are metabolic products of yeasts and/or of bacteria. Although ethanol, glycerol and carbon dioxide are the most abundant compounds that occur in wine, their contribution to the process of fermentation is rather limited and the dominant role play volatile fatty acids, higher alcohols and esters (Carascosa Santiago et al., 2011). The last part of the wine aroma is called bouquet (or floral aroma); it refers to smells that arise from the chemical reactions taking place in the course of wine ageing. In the course of time, wine aroma becomes gradually finer and finer and also more and more complex.

The aim of this study was to monitor the effect of commercial yeasts on the aromatic profiles of wine samples and to compare these experimental variants with a control sample produced by means of spontaneous fermentation. The final wine samples also passed through a sensory evaluation and the results were processed using suitable methods.

\section{MATERIALS AND METHODS}

\section{Biological material}

\section{Grape juice}

The experiment was performed with grapes of the variety Sauvignon Blanc.

The sugar concentration in grape must was estimated with a normalised sacharimeter and the result was $22.4^{\circ} \mathrm{NM}$ (i.e. $22.4 \mathrm{~kg}$ of total sugar in $100 \mathrm{~L}$ of juice). After the harvest, the temperature of juice was $19^{\circ} \mathrm{C}$; later spontaneously decreased to $15^{\circ} \mathrm{C}$. The content of total acidity was $7.91 \mathrm{~g} / \mathrm{L}$.

\section{Strains of Saccharomyces cerevisiae}

- Variant 1: Vulcaferm Sauvignon (Producer: Vulcascot Getränkeindustriebedarf Handelsgesellschaft m.b.H and Co.KG Vienna). This yeast strain is called Vulcaferm Extra. The range of recommended fermentation temperatures is 12 to $25^{\circ} \mathrm{C}$.

- Variant 2: Collection Cepage Sauvignon (Producer: Oenobrands, France). The yeast strain $n^{\circ}$ L2868 was selected in the Institut Français de la Vigne et du Vin in Nantes (France). This strain shows an excellent capability to release those aromatic thiols that participate in the unique aromatic profile of the variety Sauvignon Blanc with tones of black currant, boxwood, citrus fruit etc.

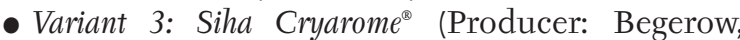
Germany). This strain of $S$. cereviside yeasts is suitable for cool fermentation and for aromatic varieties. It produces intensively aromatic, fresh, elegant and markedly spicy and fruity tones. In wines with residual sugar, these tones contribute to their increased complexity. This yeast strain is suitable not only for production of ice and straw wines but also for restarting of stuck fermentation.
- Variant 4: Oenoferm Fredo ${ }^{\oplus}$ (Producer: Erbsloh, Germany). The preparation Oenoferm Fredo is especially selected dry pure yeast strain LW317-30 that is used for inoculation of cold juices at temperatures above $8{ }^{\circ} \mathrm{C}$ as well as for the preservation of wine aroma under conditions of controlled fermentation at temperatures ranging between 13 and $17^{\circ} \mathrm{C}$. When using this yeast strain of S. cerevisiae var. bayanus, special attention was paid to reach a high degree of final fermentation even under conditions of low temperatures. This strain produces citrus and grapefruit tones as well as tones of apples, peaches and roses.

- Variant 5: Sihaferm Pure Nature (Producer:Begerow, Germany). This is an innovative yeast strain based on a combination of pure yeast culture and a wild yeast strain. This product consists of non-saccharomyces yeasts that are used within the first three days of fermentation. Thereafter, yeasts of the species S. cerevisiae are added into the fermenting juice to finish the process of fermentation without any problems. Moreover, this preparation supports also the native microflora and assures a complete fermentation of the grape juice. These yeasts produce only small amounts of such by-products as acetaldehyde, pyruvic acid, alpha-ketoglutarate, hydrogen sulfide, and volatile fatty acids (He et al., 2013).

- Variant 6: Vitilevure C $C^{\circledast}$ (Producer: Danstar, Switzerland). S. cerevisiae var. cerevisiae strain M 1157 is a preparation that is used for making of well-structured and red wines. This product is neutral and does not influence the aroma of wine considerably. It was chosen for the starting inoculation of the juice and also for a rapid fermentation. It produces also small amounts of higher alcohols.

- Variant 7: Spontaneous fermentation (Control). In this experimental variant the juice was let to ferment spontaneously and was used as a control.

\section{Experimental design}

Grapes were destemed and crushed in a destemming machine, grape must was macerated for 3 hours and thereafter gently pressed. The obtained juice was let to sediment for 12 hours at the temperature $15^{\circ} \mathrm{C}$ after the application of the enzyme Depectil clarification Fce (Danstar Ferment AG) in dose of $4 \mathrm{~g} / 100 \mathrm{~L}$. The juice was enriched with nutrients, i.e. with the preparation Actiferm (Martin Vialatte Enologie, France) in dose of $10 \mathrm{~g} / 100 \mathrm{~L}$. The prepared juice (180 litres) was thereafter divided into 7 variants with the volume of $25 \mathrm{~L}$ each. Six samples were inoculated by yeast cultures and the last one was let to ferment spontaneously as Control. The active dry wine yeast (ADWY) were revitalised for 20 minutes in a mixture of lukewarm water and juice $(1: 1)$. Thereafter, juice was added again and the yeasts were repeatedly let to be activated for another 20 minutes. After reactivation yeast starters were used for inoculation of treated grape juices. During 
the first third of fermentation, yeast nutrition Actiferm (Martin Vialatte Enologie, France) in dose of $5 \mathrm{~g} / 100 \mathrm{~L}$ was added. Fermentation was performed at the temperature of $15^{\circ} \mathrm{C}$. After the end of fermentation, wine micro samples were racked from the sediment and gradually treated with sulphur dioxide $(30 \mathrm{mg} / \mathrm{L})$. In this case, the principal requirement was to reach the maximum degree of fermentation as far as the content of wine extract was concerned. Thereafter, these micro samples were again drawn off from the sediment and clarified with bentonite so that the stable and clear samples without any turbidity (that could be caused by termolabile proteins) were obtained. After the racking, wine samples were let to age 5 months and finally they were used for experimental analyses.

\section{Monitoring of the fermentation length}

Wine samples were fermented till the stage of a minimum content of residual sugar. The concentrations of residuals sugars were measured every day during the fermentation process. Differences in the duration of the fermentation process are considered to be a characteristic trait of individual yeast products as far as their capability to ferment the grape juice.

\section{Estimation of essential analytical parameters}

\section{Determination of total acidity (OENO 52/2000)}

The total acidity was estimated by the automatic titrator TITROLINE EASY (manufacturer SI Analytics GmbH, Germany). Titrations were performed with standardized solution of $\mathrm{NaOH}$ $(0.1 \mathrm{~mol} / \mathrm{L})$ as the titration reagent, using a SenTix $21 \mathrm{pH}$ electrode. Sample $(10 \mathrm{~mL})$ was diluted with $10 \mathrm{~mL}$ of distilled water. Because of a subsequent formol titration, the sample was not titrated up to the usual $\mathrm{pH}$ value of 7.0 but up to the value of 8.1. At the end of the titration, consumption of $\mathrm{NaOH}$ solution in milliliters was read on the titrator's display. The concentration of total acidity (in $\mathrm{g} / \mathrm{L}$ ) was calculated as equivalents of tartaric acid.

\section{Determination of residual sugar, acetic acid and sugar free extract}

Residual sugar, acetic acid and sugar free extract concentrations were estimated using FTIR (ALPHA) with ATR. An ATR accessory operates by measuring the changes that occur in an internally reflected IR beam when the beam comes into contact with a sample. Before the first measurement, the spectrometer was thoroughly rinsed with deionised water and the background was determined using a deionized water. For analyses, $1 \mathrm{~mL}$ samples were taken after the fermentation with a syringe; of this sample, $0.5 \mathrm{~mL}$ was used for rinsing of the system while the remaining volume of $0.5 \mathrm{~mL}$ was analysed three times. Depending on the calibration used, the measured values were evaluated automatically using a special software Opus Wine Wizard ${ }^{\circledR}$.

\section{Analysis of aromatic compounds by means of gas chromatography}

Volatile organic compounds were separated from wine samples using the until now unpublished method of l-l equilibrium microextraction by methyl-terc-butyl ether. $50 \mu \mathrm{L}$ of a solution of 2-nonanol in ethanol (used as an internal standard in concentration $400 \mathrm{mg} / \mathrm{L}$ ) were pipetted into a $25 \mathrm{~mL}$ volumetric flask. Thereafter the flask was filled up to the adjustment line with the wine and mixed with $1.5 \mathrm{~mL}$ of the extraction solvent (i.e. MTBE with an addition of $1 \%$ v.v. cyclohexane). The mixture was thoroughly shaken and the supernatant (organic layer with a part of produced emulsion) was taken off and transferred into a micro test tube; the sample was centrifuged and a clear organic phase was dried using anhydrous magnesium sulphate. This extract was used for a GC-MS analysis. Instrumentation: Shimadzu GC-17A; Autosampler: AOC-5000; Detector: QP-5050A. Software: GCsolution. Separation conditions: Column: DB-WAX $30 \mathrm{~m} \times 0.25 \mathrm{~mm} ; \quad 0.25 \mu \mathrm{m}$ of the stationary phase (polyethylene glycol). Detector voltage $1.5 \mathrm{kV}$. Individual compounds were identified on the base of the MS spectrum and retention time interval.

\section{Separation conditions}

Spray sample volume: $1 \mu \mathrm{L}$; split ratio 1 : 5 . Flow of carrier gas (He): $1 \mathrm{~mL} / \mathrm{min}$ (linear velocity of carrier gas $36 \mathrm{~cm} / \mathrm{s}$ ). Temperature in the spray chamber: $180^{\circ} \mathrm{C}$. The initial temperature of the column space $\left(15^{\circ} \mathrm{C}\right)$ was maintained for a time interval of 3.5 min.; thereafter, the following temperature gradients were used: up to $75^{\circ} \mathrm{C}$ by $6{ }^{\circ} \mathrm{C}$ per minute, up to $126{ }^{\circ} \mathrm{C}$ by $3{ }^{\circ} \mathrm{C}$ per minute, up to $190{ }^{\circ} \mathrm{C}$ by $4^{\circ} \mathrm{C}$ per minute and up to $250{ }^{\circ} \mathrm{C}$ by $5^{\circ} \mathrm{C}$ per minute. The final temperature was maintained for a period of 6.5 minutes. The total time interval of analysis was 60 minutes. In the SCAN modem the detector operated with the interval of $0.25 \mathrm{~s}$ within the range of 14-264. The voltage of the detector was $1.5 \mathrm{kV}$. The quantification was performed on the base of a comparison of the sample peak area with the external standard corrected to the internal standard 2-nonanol (16 mg/L).

\section{Calibration Curves}

For quantification, five-point calibration curves were constructed for all standard compounds, containing the internal standard 2-nonanol. For that purpose, a synthetic wine model sample (12\% ethanol and $4 \mathrm{~g} / \mathrm{L}$ tartaric acid with $\mathrm{pH} 3.4$, adjusted by sodium hydroxide solution) was prepared, containing the known amounts of the standards, which was extracted and analyzed by GC-MS as above-mentioned. Extraction of volatile compounds was performed three times for each wine and then each extract was injected into the GC/MS. In order to quantify the volatile compounds present 
in the wines, the relative peak area (in the total ion chromatogram) of each analyte from the wine to the internal standard was compared to those obtained for the standards, taking into account the dilution of the samples. The concentration of the volatile compounds for which there was no pure reference was obtained using the calibration curve of one of the standard compounds with the most similar chemical structure, i.e., belonging to the same class of compounds.

\section{Recovery}

For the recovery of the method, it was established by spiking a wine sample with a standard working solution at three concentrations and assaying it in triplicate. The concentrations of the volatile compounds in the nonspiked wine were subtracted from the concentrations in the spiked wine and the recovery percentages $(R \%)$ were calculated by dividing the calculated concentrations by the expected concentrations. Calibration regression lines for each compound and recovery percentage after the extraction process in Tab. VI.

\section{Sensory evaluation}

Altogether 8 experts participated in the sensory evaluation. Wine samples were evaluated using the UIOE (International Union of Oenologists) 100-point scale system. The evaluation was focused on the aromatic profile of wine sample and on the extract effect on the full taste and harmony of individual wine samples. The final result is average of 8 evaluations.

\section{Statistical analysis}

Statistical analyses and graphs were generated using Excel 2007 (Microsoft Office, USA) and Statistica 10 (Copyright $@$ StatSoft). a non-parametric ANOVA-Kruskal-Wallis test was used for statistical analyses of volatile compounds. Results are expressed as mean \pm standard deviation. Differences with $\mathrm{P}<0.05$ were considered significant.

\section{RESULTS AND DISCUSSION}

Based on yeast cultures used within the course of fermentation, it is possible to separate this process into two parts, viz. The spontaneous fermentation and the fermentation running after the addition of pure yeast cultures. The spontaneous fermentation is the result of activities of the native microflora that exists on the surface (skins) of berries (Lambrechts and Pretorius, 2000). Although these yeasts may produce wine of a good quality the course of this type of fermentation and its results cannot be fully controlled. Moreover, with the increasing industrialisation of viticulture, the possibility to control the autochthonous microflora participating in the process of natural fermentation (Schneider, 2005).

The application of pure yeast cultures means that the fermentation is the result of activities of only one strain, race and/or variety of yeast that are used as a starting culture. Although wines produced in this way are well fermented and without strange tones, they lack the diversity of a wide spectrum of aromatic compounds. Pure yeast cultures usually consist only of microorganisms that are members of the genus Saccharomyces sp. (Lee et al., 2012).

\section{Monitoring of the fermentation process}

Duration of fermentation of individual samples are presented in Tab. I. The longest periods of fermentation were recorded in Variant 5 with Siha Pure Nature yeasts, in Variant 6 with Vitilevure $C$ yeasts, and in control Variant 7. In Variants 5 and 7, the duration of the fermentation process was probably influenced by the fact that non-saccharomyces yeasts were active at the beginning so that the fermentation run in a relatively slow manner. Contents of total titratable acids, acetic acid, residual sugar and sugar free extract are also presented in Tab. I.

As far as the total acidity was concerned, Schneider (2005) mentioned that in variants with individual yeast strains the maximum differences in contents of total titratable acids were $0.5 \mathrm{~g} / \mathrm{L}$; it seems that this fact does not play an important role when deciding about yeast strains. In our experiment, the variation range of maximum (9.9 g/L) and minimum (8.9 g/L) values was $1 \mathrm{~g} / \mathrm{L}$. This confirms the previous study that the yeast strain selection does not affect total acidity. Sparkling wines may be the only exception because they must contain higher amounts of acids (Schneider, 2005). The lowest and the highest levels of acids were estimated in samples fermented with varietal and psychrophilous yeast strains, respectively (Tab. 1).

I: Contents of essential analytical parameters and duration of fermentation in individual experimental variants in Sauvignon wine variety after fermentation with different yeast strains of S. cerevisiae

\begin{tabular}{lccccccc}
\hline Parameter/Variant & $\mathbf{1}$ & $\mathbf{2}$ & $\mathbf{3}$ & $\mathbf{4}$ & $\mathbf{5}$ & $\mathbf{6}$ & $\mathbf{7}$ \\
\hline Total titratable acids (g/L) & 8.9 & 8.9 & 9.6 & 9.9 & 9.2 & 9.8 & 9.2 \\
Acetic acid (mg/L) & 175 & 340 & 445 & 340 & 290 & 445 & 370 \\
Residual sugar (g/L) & 2.03 & 1.85 & 1.80 & 2.10 & 2.31 & 8.40 & 2.90 \\
Sugar free extract (g/L) & 20.3 & 19.3 & 21.8 & 19.9 & 16.0 & 23.0 & 20.9 \\
Duration of fermentation (days) & 13 & 15 & 17 & 13 & 26 & 23 & 23 \\
\hline
\end{tabular}

Variants: 1 - Vulcaferm Sauvignon; 2 - Collection Cepage Sauvignon; 3 - Siha Cryoarome; 4 - Oenoferm Fredo; 5 - Siha Pure Nature; 6 - Vitilevure C; 7 - Spontaneous fermentation 
Acetic acid belongs to the group of volatile acids and it is undesirable in wine. This acid is produced predominantly by oxidation of ethanol. However, it can be also imported into wine with grapes and small amounts of acetic acid may be produced by yeasts under anaerobic conditions (Cordente et al., 2013). The lowest and the highest contents of this acid were found out in Variant 1 (yeasts Vulcaferm Sauvignon-175 mg/L) and in Variant 3 (Siha Cryoarome-445 mg/L), respectively.

With the exception of Variant 6 (Vitilevure C yeasts) concentrations of residual sugar were lower than $4 \mathrm{~g} / \mathrm{L}$. In this case, the process of fermentation was slow and the concentration of residual sugar was $8.4 \mathrm{~g} / \mathrm{L}$. Steidl (2001b) referred that the spontaneous fermentation is characterised by increased contents of glycerol, higher alcohols, and volatile acids. Often the process of fermentation is spontaneously finished and wine then contains residual sugar. Jolly et. al. (2003) compared fermentation processes caused by non-saccharomyces yeasts and by pure yeast cultures. Their results indicated that in spontaneously fermented samples the process of fermentation could not be finished and that wine contained residual sugar. The process of fermentation was spontaneously finished at the level of 2,9 $\mathrm{g} / \mathrm{L}$ of residual sugar.

\section{Estimation of aromatic compounds}

Aromatic compounds were estimated using the GC-MS analysis. Of obtained data those aromatic substances were selected, which were produced also by yeasts and increase their amount.

Zoecklein (1997) wrote that an increase in the content of aromatic compounds produced within the process of spontaneous fermentation may be the result of activities of more yeast species and genera than in juices inoculated with cultural yeast.

This was really corroborated in the experimental part of this study: in Variant 7, production of esters and higher alcohols was the second highest while the acetate level was the lowest at all.

\section{Estimation of some selected alcohols}

As far as higher alcohols are concerned, amylalcohols are the most important; of these, three isomers, viz. pentan-1-ol (starch), 3-methylbutan-1-ol (isoamyl alcohol) and 2-methylbutan-1-ol (optically active amyl alcohol). Although in higher concentrations the smell of these amylalcohols is acrid, it is pleasant and desirable if they are present in lower concentrations (Clarke, 2004). Aroma descriptors and concentrations of alcohols under study are presented in Tab. II.

\section{Estimation of ethyl esters}

Esters are considered as an important wine component. They are the cause of fermentation aroma and sometimes participate also in the tertiary aroma that is developing during the process of wine ageing. Esters are products resulting from chemical reactions of alcohol and organic acids; during these reactions a water molecule is produced

II: Concentrations of selected higher alcohols in Sauvignon wine variety after fermentation with different yeast strains of S. cerevisiae

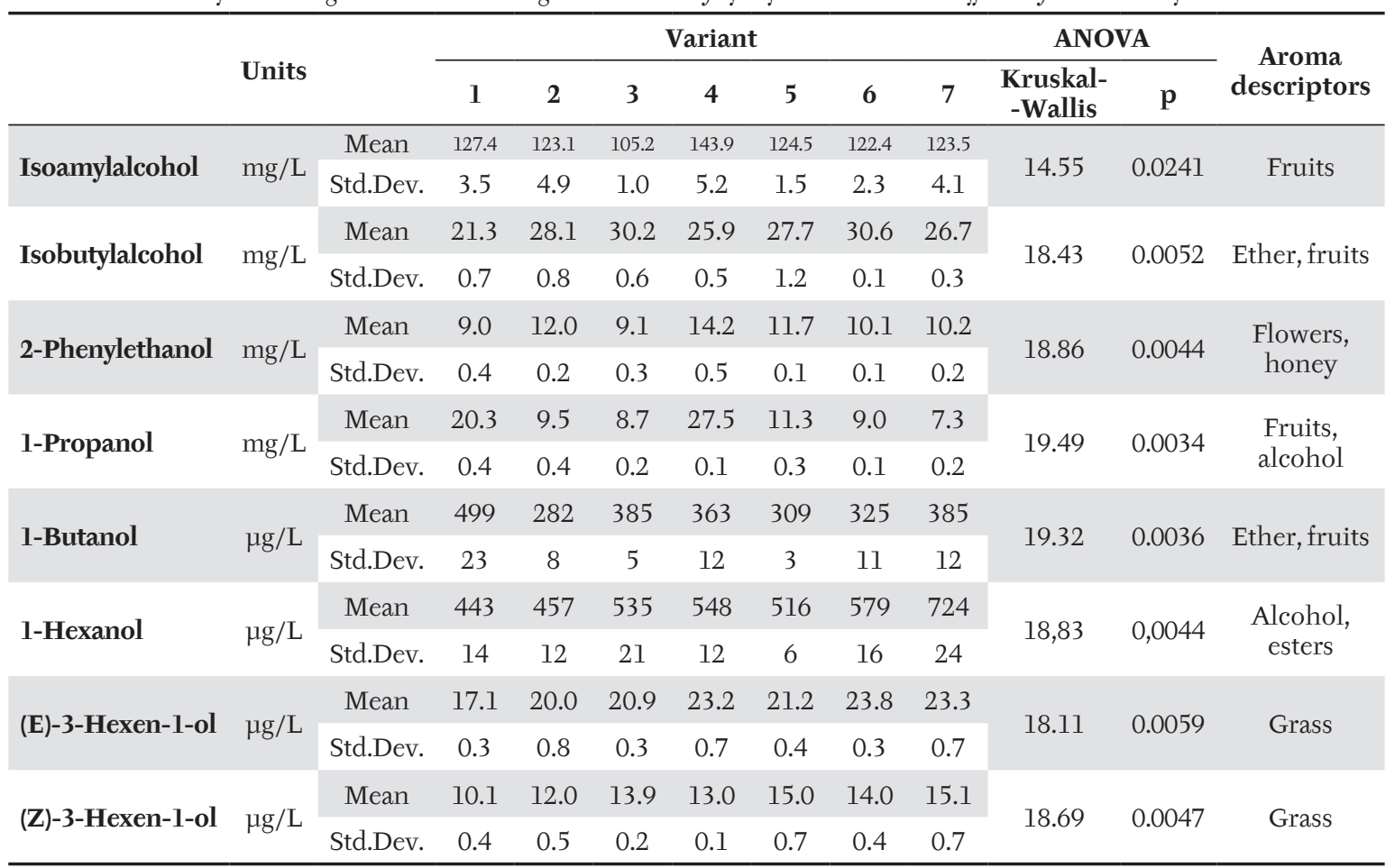

Variants: 1 - Vulcaferm Sauvignon; 2 - Collection Cepage Sauvignon; 3 - Siha Cryoarome; 4 - Oenoferm Fredo; 5 - Siha Pure Nature; 6 - Vitilevure C; 7 - Spontaneous fermentation 
as well. At a significant concentration, they are also the product of yeast metabolism at lower temperature $\left(15^{\circ} \mathrm{C}\right)$. White wines contain higher amounts of esters; this corresponds to a well-known effect of vinification at lower temperatures. Ethyl esters of C4-C10 fatty acids resemble aroma of fruit. Lower aliphatic esters resemble not only tones of tropical fruit (banana, pineapple) but also of apples and pears. Smell of higher homologs resembles more likely soapy and oily aroma (Clarke, 2004). According to the value $\mathrm{p}$ from the statistical analysis, the concentrations of volatile compounds between the different variants can be considered statistically significantly different.

Measured contents of ethyl esters are presented in Tab. III.

The most intensive production of ethyl hexanoate (up to $682 \mu \mathrm{g} / \mathrm{L}$ ) was observed in Variant 7 (Spontaneous fermentation). The highest amounts of ethyl octanoate were in Variants $7(735 \mu \mathrm{g} / \mathrm{L})$ (Spontaneous fermentation) and 4 (717 $\mu \mathrm{g} / \mathrm{L})$ (Oenoferm Fredo). The variation range was as much as $355 \mu \mathrm{g} / \mathrm{L}$. Higher amounts of ethyl decanoate were produced in Variants $4(160 \mu \mathrm{g} / \mathrm{L})$ (Oenoferm Fredo), 1 (154 $\mu \mathrm{g} / \mathrm{L})$ (BS Type Sauvignon) and 7 (162 $\mu \mathrm{g} / \mathrm{L}) \quad$ (Spontaneous fermentation). As shown in Tab. 3, the highest concentrations of investigated ethyl esters were produced in Variants 1 (Vulcaferm Sauvignon), 4 (Oenoferm Fredo), and 7 (Spontaneous fermentation). According to the value $\mathrm{p}$ from the statistical analysis, the concentrations of volatile compounds between the different variants can be considered statistically significantly different.

Steidel (2001) has written in his book that the current trend is to use yeast cultures producing high amounts of esters (partly this is also because of practical reasons). Although this practice makes the majority of customers satisfied, its negative aspect represents the fact that the varietal character of produced wine may blurred, overlapped or even wiped of and this may be a serious problem just in case of Sauvignon blanc. On the other hand, however, the application of a spontaneous fermentation may be sometimes extremely risky because it may result in an uncontrolled occurrence of aromatic compounds that are very unpleasant from the sensory point of view (Steidl, 200la). This means that for the variety Sauvignon Blanc the most suitable yeast strains are those that help to release moderate amounts of esters and high quantities of fruity thiols from bonded form (Ribéreau-Gayon et al., 2006).

\section{Estimation of acetates}

Acetates are salts or esters of acetic acid and are mostly well soluble in water. Regarding the fact that they are produced above all under oxidative conditions, they occur more often in sherry wines (Jackson, 2002).

Amounts of produced acetates are presented in Tab.VI.

The most important of them is isoamyl acetate that has a pronounced banana aroma. The highest amounts of this compound were found out in Variants 1 (Vulcaferm Sauvignon) and 4 (Oenoferm Fredo). The highest production of 2-phenylethyl acetate was recorded in Variants 4 (Oenoferm Fredo), 2 (Colection Cepage Sauvignon) and 1 (Vulcaferm Sauvignon). The highest amounts of isobutyl acetate were produced in Variants 3 (Siha Cryoarome), 4 (Oenoferm Fredo) and 1 (Vulcaferm Sauvignon). According to the value $\mathrm{p}$ from the statistical analysis, the concentrations of volatile compounds between the different variants can be considered statistically significantly different.

\section{Sensory evaluation of wine samples}

Results of this sensory evaluation of tested wines are presented in Tab. 5 .

As the best was evaluated wine samples from Variant 4 (Oenoferm Fredo) and as the worst was evaluated Variants 2 (Collection Cepage Sauvignon) and 7 (Spontaneous fermentation).

As far as higher alcohols were concerned, concentrations of isoamyl alcohol and 1-propanol were the highest. These compounds cause a pronounced fruity alcoholic fragrance.

The lowest point evaluation received samples from Variants 2 and 7. These samples showed a low content of acetates. The lowest content of ethyl esters was measured in Variant 2 (Cepage Collection Sauvignon yeasts). On the other hand, wine sample of Variant 7 (Spontaneous fermentation) contained

III: Concentrations of ethyl esters in Sauvignon wine variety after fermentation with different yeast strains of S. cerevisiae

\begin{tabular}{|c|c|c|c|c|c|c|c|c|c|c|c|c|}
\hline & \multirow[b]{2}{*}{ Units } & & \multicolumn{7}{|c|}{ Variant } & \multicolumn{2}{|c|}{ ANOVA } & \multirow{2}{*}{$\begin{array}{c}\text { Aroma } \\
\text { descriptors }\end{array}$} \\
\hline & & & 1 & 2 & 3 & 4 & 5 & 6 & 7 & $\begin{array}{c}\text { Kruskal- } \\
\text {-Wallis }\end{array}$ & $\mathrm{p}$ & \\
\hline \multirow{2}{*}{ Ethyl-hexanoate } & \multirow{2}{*}{$\mu \mathrm{g} / \mathrm{L}$} & Mean & 583 & 358 & 499 & 661 & 354 & 346 & 688 & \multirow{2}{*}{18.52} & \multirow{2}{*}{0.005} & \multirow{2}{*}{$\begin{array}{c}\text { Pineapple, } \\
\text { banana }\end{array}$} \\
\hline & & Std.Dev. & 23 & 8 & 4 & 23 & 6 & 6 & 24 & & & \\
\hline \multirow{2}{*}{ Ethyl-octanoate } & \multirow{2}{*}{$\mu \mathrm{g} / \mathrm{L}$} & Mean & 683 & 402 & 532 & 717 & 379 & 363 & 734 & \multirow{2}{*}{18.99} & \multirow{2}{*}{0.0042} & \multirow{2}{*}{ Raisins } \\
\hline & & Std.Dev. & 21 & 6 & 4 & 30 & 13 & 13 & 5 & & & \\
\hline \multirow{2}{*}{ Ethyl-decanoate } & \multirow{2}{*}{$\mu \mathrm{g} / \mathrm{L}$} & Mean & 155 & 102 & 117 & 161 & 90 & 75 & 161 & \multirow{2}{*}{18.87} & \multirow{2}{*}{0.0044} & \multirow{2}{*}{$\begin{array}{l}\text { Orange, } \\
\text { flowers }\end{array}$} \\
\hline & & Std.Dev. & 3 & 3 & 5 & 6 & 2 & 2 & 5 & & & \\
\hline
\end{tabular}

Variants: 1 - Vulcaferm Sauvignon; 2 - Collection Cepage Sauvignon; 3 - Siha Cryoarome; 4 - Oenoferm Fredo; 5 - Siha Pure Nature; 6 - Vitilevure C; 7 - Spontaneous fermentation 
the highest amount of ethyl esters; this was manifested in an unbalanced aroma and presence of smells that were not typical for the variety Sauvignon Blanc. Production of higher alcohols was only on the average level.
Analysis of aromatic compounds by means of gas chromatography

Calibration regression lines for selected aromatic compounds and recovery percentage after the extraction process are in Tab. VI.

IV: Concentrations of acetates in Sauvignon wine variety after fermentation with different yeast strains of S. cerevisiae

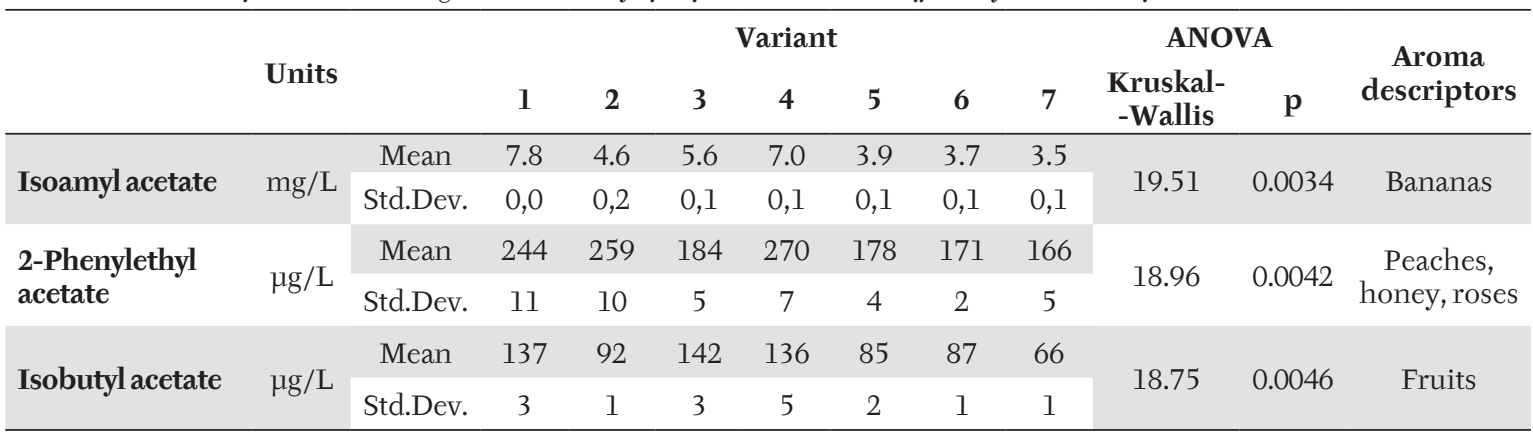

Variants: 1 - Vulcaferm Sauvignon; 2 - Collection Cepage Sauvignon; 3 - Siha Cryoarome; 4 - Oenoferm Fredo; 5 - Siha Pure Nature; 6 - Vitilevure C; 7 - Spontaneous fermentation

V: Results of sensory evaluation in Sauvignon wine variety after fermentation with different yeast strains of S. cerevisiae

\begin{tabular}{ccc}
\hline Variant & Mean value (points) \\
\hline $\mathbf{1}$ & 81.9 \\
$\mathbf{3}$ & 78.4 \\
$\mathbf{4}$ & 80.1 & $\mathbf{8 5 . 8}$ \\
$\mathbf{5}$ & 82.3 \\
$\mathbf{6}$ & 82.1 \\
\hline $\mathbf{7}$ & 78.5 \\
\hline
\end{tabular}

Variants: 1 - Vulcaferm Sauvignon; 2 - Collection Cepage Sauvignon; 3 - Siha Cryoarome; 4 - Oenoferm Fredo; 5 - Siha Pure Nature; 6 - Vitilevure C; 7 - Spontaneous fermentation

VI: Calibration regression lines for each compound and recovery percentage after the extraction process.

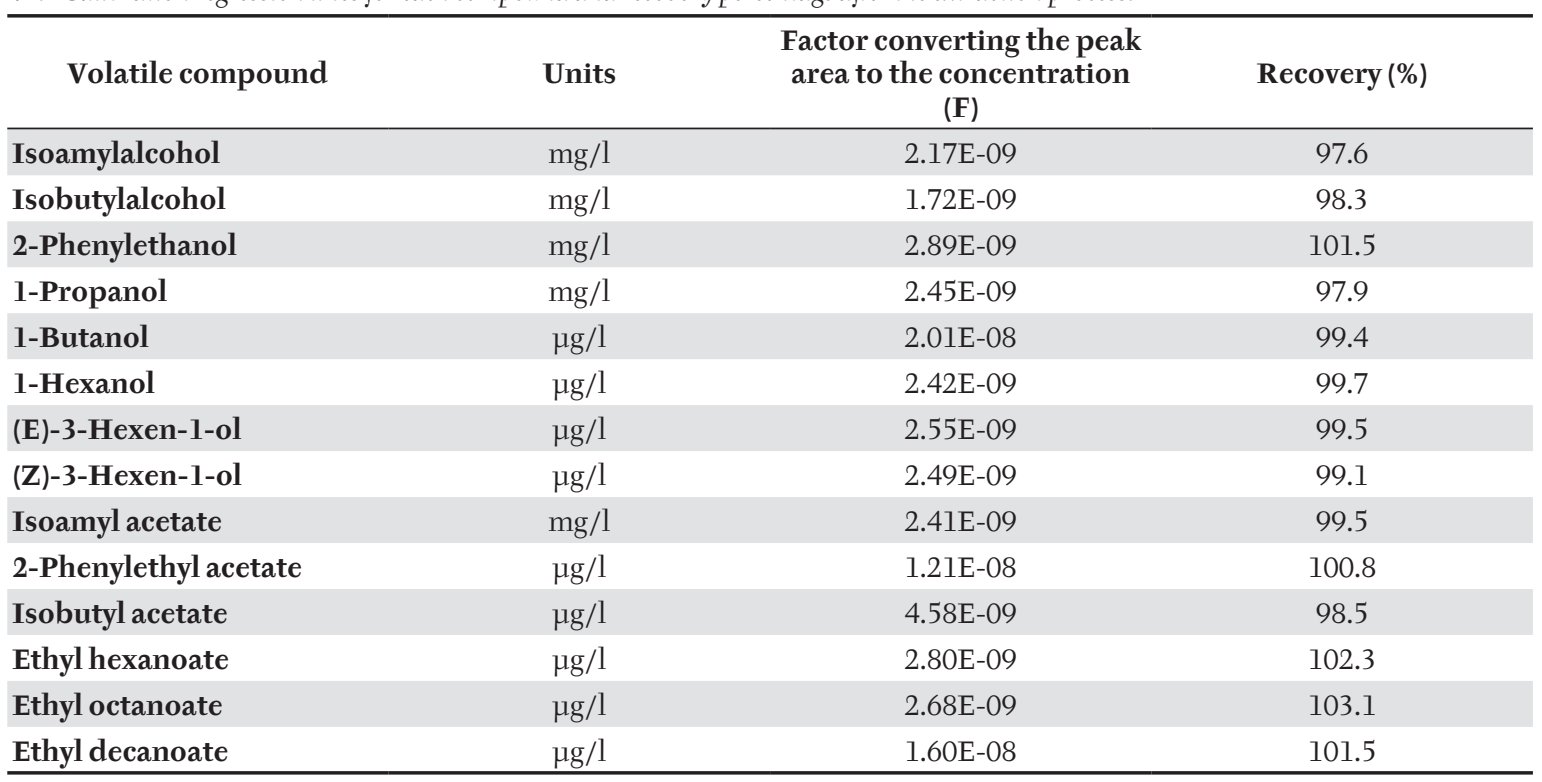

Calibration regression line: $\mathrm{y}=\mathrm{F} . \mathrm{x}, \mathrm{x}$ - peak area, $\mathrm{y}$ - concentration of volatile compound. 


\section{CONCLUSION}

Our experiments corroborated the assumption that yeasts produce minor metabolites (e.g. higher alcohols, ethyl esters and acetates) in the course of the fermentation process. Yeast preparation Vulcaferm Sauvignon and Oenoferm Fredo produced high quantities of ethyl esters and acetates. Individual types of yeast produced wines with different concentrations of residual sugar; these results were influenced by the applied yeast strain.

The highest content of esters under study was found out in Variant 7 (Spontaneous fermentation); in this case, contents of ethyl hexanoate, ethyl octanoate and ethyl decanoate were $682 \mu \mathrm{g} / \mathrm{L}, 735 \mu \mathrm{g} / \mathrm{L}$ and $162 \mu \mathrm{g} / \mathrm{L}$, respectively. The highest content of acetates was recorded in Variant 1 (Vulcaferm Sauvignon); in this case, contents of isoamyl acetate, 2-phenylethyl acetate and isobutyl acetate were $7.8 \mathrm{mg} / \mathrm{L}, 244 \mu \mathrm{g} / \mathrm{L}$ and $137 \mu \mathrm{g} / \mathrm{L}$, respectively. On the other hand, the lowest content of esters was recorded in Variant 6 (Vitilevure C); in this case, contents of ethyl hexanoate ethyl octanoate and ethyl decanoate were $344 \mu \mathrm{g} / \mathrm{L}, 363 \mu \mathrm{g} / \mathrm{L}$ and $76 \mu \mathrm{g} / \mathrm{L}$, respectively. The lowest content of acetates was found in Variant 7 (Spontaneous fermentation); in this case, contents of isoamyl acetate, 2-phenylethyl acetate and isobutyl acetate were $3.5 \mathrm{mg} / \mathrm{L}, 169 \mu \mathrm{g} / \mathrm{L}$ and $66 \mu \mathrm{g} / \mathrm{L})$, respectively. There were marked differences in levels of acetic acid. In Variants 3 (Siha Cryoarome) and 6 (Vitilevure C), the contents of this acid were $445 \mathrm{mg} / \mathrm{L}$ while in Variant 1 (Vulcaferm Sauvignon) it was only $175 \mathrm{mg} / \mathrm{L}$ ).

As far as the sensory evaluation was concerned, the best wine sample was considered in Variant 4 (Oenoferm Fredo). The aroma and taste of this wine were very good as well as its harmony. The lowest sensory quality was found out in Variants 2 (Collection Cepage Sauvignon) and 7 (Spontaneous fermentation).

Acknowledgement

The support from financial sources of the project IGA 14/2014/591 ZF is highly appreciated.

\section{REFERENCES}

CARASCOSA SANTIAGO, A., MUNOZ, R. and GONZÁLES GARCIA, R. 2011. Molecular wine microbiology. $1^{\text {st }}$ Edition. Boston ed.: Academic Press.

CLARKE, R. and BAKKER, J. 2004. Wine flavour chemistry. Chichester, UK: John Wiley and Sons.

CORDENTE, A. G., CORDERO-BUESO, G., PRETORIUS, I. S. et al. 2013. Novel wine yeast with mutations in yeast that produce less acetic acid during fermentation. Fems Yeast Research, (13): 62-73.

HE, G. F., SUI, J. L., DU, J. H. and LIN, J. 2013. Characteristics and antioxidant capacities of five hawthorn wines fermented by different wine yeasts. Journal of the Institute of Brewing, 119(4): 321-327.

JACKSON, R. S. 2002. Wine tasting: a professional handbook. New York, USA: Academic Press.

JOLLY, N. P., AUGUSTYN, O. P. H. and PRETORIUS, I. S. 2003. The effect of non-Saccharomyces yeasts on fermentation and wine quality. South African Journal of Enology and Viticulture, 24(2): 55-62.

LAMBRECHTS, M. G. and PRETORIUS, I. S. 2000. Yeast and its importance to wine aroma: A review. South African Journal of Enology and Viticulture, 21: 97-129.

LEE, P. R., SAPUTRA, A., YU, B., CURRAN, P. and LIU, S. Q. 2012. Effects of Pure and Mixed-Cultures of Saccharomyces cerevisiae and Williopsis saturnus on the Volatile Profiles of Grape Wine. Food Biotechnology, 26: 307-325.

MENDES FERREIRA, A., CLIMACO, M. C. and MENDES FAIA, A. 2001. The role of non-Saccharomyces species in releasing glycosidic bound fraction of grape aroma components a preliminary study. Journal of Applied Microbiology, 91(1):67-71.

MORENO-ARRIBAS, M. and POLO, A. M. 2009. Wine chemistry and biochemistry. New York: Springer.

RIBÉREAU-GAYON, P., DUBOURDIEU, D., and DONÉCHE, A. B. 2006. Handbook of enology. Volume 2: he chemistry of wine stabilization and treatments. $2^{\text {nd }}$ Edition. Chichester, UK: John Wiley \& Sons.

SCHNEIDER, V. 2005. Einfluss von Hefe und Gärung auf die Säure. $11^{\text {th }}$ Edition. Der Winzer Zeitung.

STEIDL, R. 2001a. Kellerwirtschat. Cadmos Verlag Gmbh.

STEIDL, R. and RENNER, W. 2001b. Gärprobleme. Ursachen, Beurteilung, Behebung Verlag Eugen Ulmer.

ZOECKLEIN, B. W., MARCY, J.E., WILIAMS, J. M. and JASINSKY, Y. 1997. Effect of native yeasts and selected strains of Saccharomyces cerevisiae on glycosyl glucose, potential volatile terpens, and selected aglycones of White Riesling. Journal of food composition and analysis, 10(1): 55-65 